\title{
Case Report \\ Primary Retroperitoneal Malignant Melanoma with Involvement of Iliac Artery and Vein
}

\author{
Aislyn Oulee $\mathbb{D}^{1}{ }^{1}$ Ling $\mathrm{Xu}^{2}{ }^{2}$ and Scott Worswick $\mathbb{D}^{3}$ \\ ${ }^{1}$ University of California Riverside School of Medicine, Riverside, CA, USA \\ ${ }^{2}$ Kaiser Permanente Riverside Medical Center, Riverside, CA, USA \\ ${ }^{3}$ Department of Dermatology, Keck School of Medicine at the University of Southern California, Los Angeles, CA, USA
}

Correspondence should be addressed to Aislyn Oulee; aoule001@medsch.ucr.edu

Received 10 April 2021; Accepted 28 August 2021; Published 6 September 2021

Academic Editor: Gerald S. Supinski

Copyright (C) 2021 Aislyn Oulee et al. This is an open access article distributed under the Creative Commons Attribution License, which permits unrestricted use, distribution, and reproduction in any medium, provided the original work is properly cited.

Primary retroperitoneal melanoma is a very rare extracutaneous presentation of melanoma. In this case report, we present a 65year-old female with unilateral lower extremity edema secondary to occlusion of iliac vessels by a primary retroperitoneal melanoma tumor. We also review the findings in other cases previously described in the literature.

\section{Introduction}

Primary retroperitoneal melanoma (PRM) is an extremely rare form of malignant extracutaneous melanoma with a poor prognosis. Although malignant melanomas arise from the skin in vast majority of cases, they can also appear in other organs where melanocytes are present including the eye, meninges and mucosa, and much less commonly in the retroperitoneal space. Diagnosis of a retroperitoneal melanoma requires a thorough cutaneous, mucosal, and ocular exam to ensure there are no primary lesions in these areas that may have metastasized to the retroperitoneal space. In this case report, we present a rare case of primary retroperitoneal melanoma with involvement of the left iliac artery and vein.

\section{Case Report}

A 65-year-old Caucasian female presented with a two-week history of left lower extremity swelling and pain. The patient stated that the swelling slightly improved with elevation of her legs and that the pain was partially alleviated with NSAIDs. The patient denied any shortness of breath, recent trauma, fever, chest pain, or unexplained weight loss. She had a past medical history significant for inflammatory polyarthritis (on methotrexate and Humira), hyperlipidemia, hypertension, asthma-COPD overlap syndrome, osteopenia, and paroxysmal atrial fibrillation. She had been taking warfarin for atrial fibrillation with international normalized ratio (INR) levels within the therapeutic range. The patient had a history of three-pack years of smoking but stated she quit approximately 40 years ago.

On physical examination, the presence of pitting edema of her left lower extremity was noted (Figure 1). There were strong peripheral pulses, and her abdomen was soft and nondistended. Blood work was significant for severe hypokalemia $(2.8 \mathrm{mEq} / \mathrm{L})$, which was repleted in clinic. Both erythrocyte sedimentation rates and C-reactive protein levels were checked and found to be elevated at $35.0 \mathrm{~mm} / \mathrm{hr}$ and $30.1 \mathrm{mg} / \mathrm{L}$, respectively. An ultrasound examination of the left lower extremity was negative for deep venous thrombosis (DVT). A computed tomography (CT) angiography of the abdomen/pelvis was then performed and revealed a large heterogeneous left pelvic retroperitoneal mass centered at the left iliac chain region spanning $8.7 \times 6.9 \times 8.5 \mathrm{~cm}$ with probable compression/occlusion of the adjacent iliac vein (Figure 2). Based on the imaging study, the differential diagnosis included sarcoma, lymphoma, ovarian neoplasm, or germ cell tumor.

A CT-guided abdominal mass needle core biopsy was performed, and the sample was sent for $\mathrm{H} \& \mathrm{E}$ staining (Figure 3(a)) as well as immunohistochemical (IHC) 


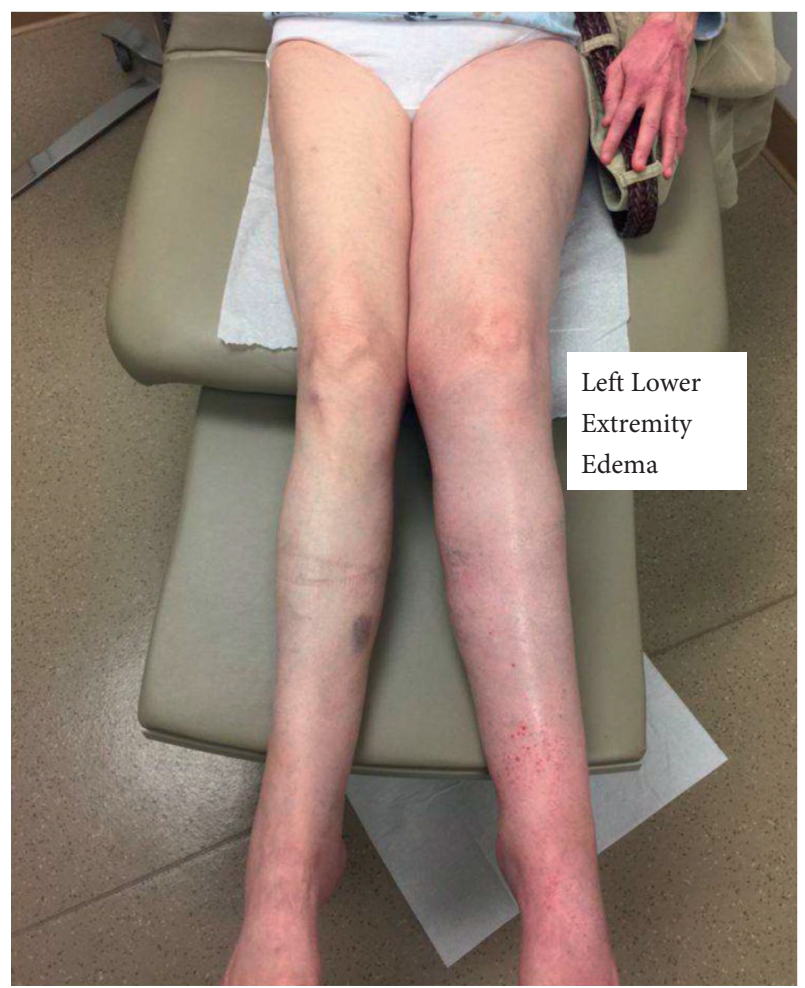

Figure 1: Patient's initial presentation of left lower extremity edema.

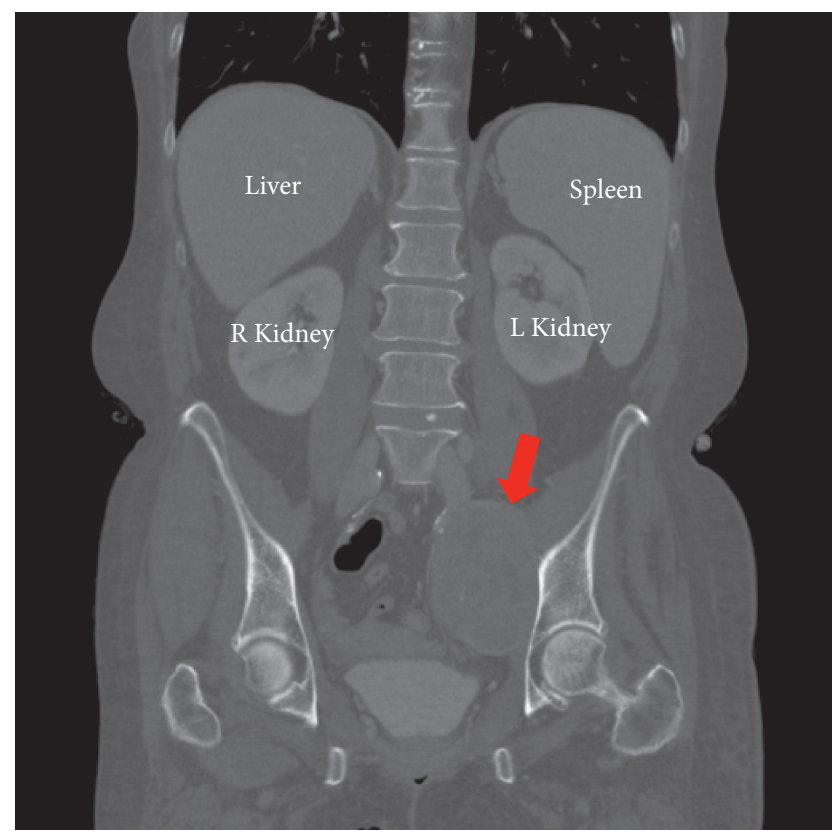

Figure 2: Computed tomography of the abdomen reveals $8.7 \times 6.9 \times 8.5 \mathrm{~cm}$ mass (red arrow) in the retroperitoneal space.

staining. Immunostaining showed that the tumor cells were diffusely and strongly positive for SOX10 (Figure 3(b)) but were negative for CK7, CK20, GATA3, and PAX8. These immunohistochemical stain findings support a diagnosis of melanoma. The tumor cells were also positive for S100 immunostaining (Figure 3(c)) and BRAF V600E mutation, thereby further confirming the diagnosis. Upon review of the case and the CT scan, surgical oncology determined that the mass was surgically unresectable due to invasion of the adjacent iliac vessels. A comprehensive workup was performed to search for primary and secondary involvement of other sites, including an MRI brain and brainstem with no contrast and a full body PET scan, both of which were unremarkable.

The patient was referred to a dermatologist for a detailed skin examination, and no primary lesion was found. Therefore, a diagnosis of primary retroperitoneal melanoma was rendered. The patient was also referred to an oncologist who offered the patient clinical trial for EA6134 (a randomized phase III trial of dabrafenib and trametinib followed by ipilimumab and nivolumab) since the tumor contained the mutation BRAF V600. Five months after being started on the clinical trial, the patient was admitted to the hospital with shortness of breath and encephalopathy. She was evaluated by an oncologist who determined that her encephalopathy was the result of her chemotherapy, and her participation in the trial was therefore withdrawn. The patient was discharged to a hospice facility and succumbed to the disease one month later, six months after her initial diagnosis.

\section{Discussion}

Melanoma, a malignancy arising from melanocytes, is the deadliest form of cutaneous malignancy. Most malignant melanomas arise from the skin, and only $5 \%$ of all primary melanomas arise from extracutaneous tissues [1]. Extracutaneous malignant melanomas are extremely rare and aggressive lesions, and therefore the rarity and aggressive nature of this disease make its diagnosis and treatment a challenging task. To date, only 7 cases of PRM have been reported in the English-language literature (Table 1) [2-8]. The initial symptoms of primary retroperitoneal melanoma can be nonspecific and include fatigue, weight loss, anorexia, and leg swelling; however, of these 7 previously reported cases and our own $8^{\text {th }}$ case, some specific presenting signs can be identified. In 4 of the 8 cases (50\%), patients presented with abdominal pain, in three cases (38\%) with abdominal distension/fullness, and in one case with postmenopausal vaginal bleeding $[3-5,8]$. CT plays an important role in the diagnosis of primary retroperitoneal melanoma as it can localize the tumor [9]. However, immunohistochemical stains are required for the definitive diagnosis of PRM. Both cutaneous and noncutaneous melanomas exhibit the same immunohistochemical and structural features [2]. Despite the variety of immunohistochemical markers for melanoma, S100 remains the most sensitive [10]. In addition, SOX10 is a transcription factor that has also been shown to be a sensitive marker of melanoma [11]. Both S100 and SOX10 immunostains were positive in our case. The patient's melanoma also contained a mutation in the BRAF gene, which is present in approximately $50 \%$ of cases of advanced melanoma [12]. Negative immunostaining for CK7, CK20, GATA3, and PAX8 also played a vital role in ruling out other probable malignancies and arriving at the diagnosis of melanoma. For instance, PAX8 is a specific and sensitive 


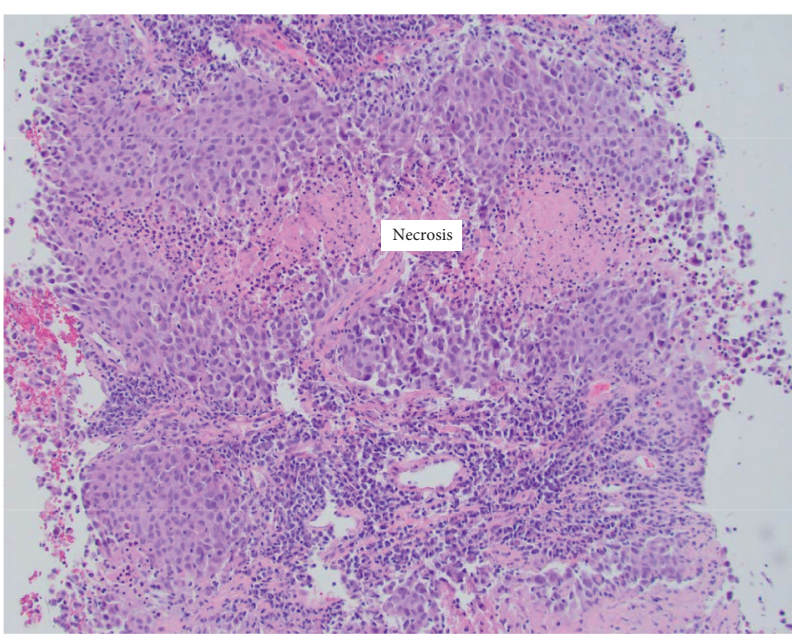

(a)

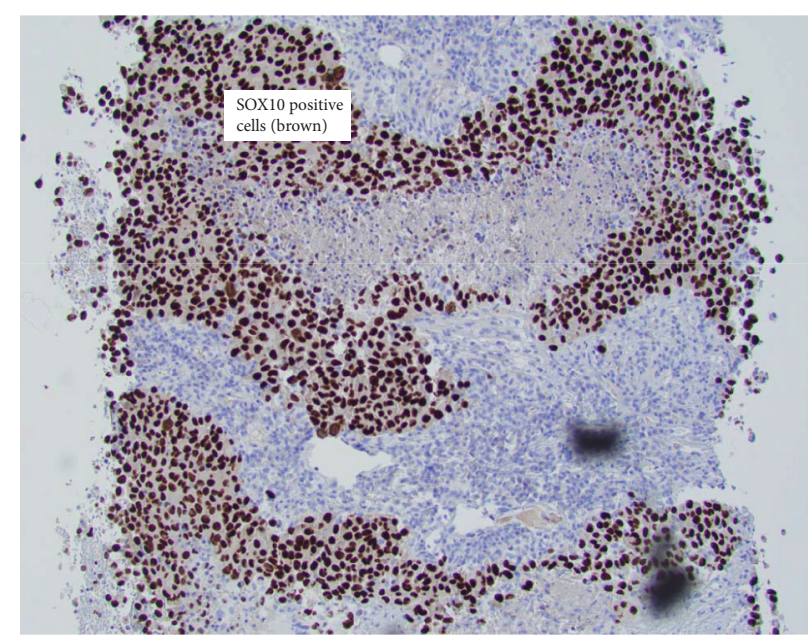

(b)

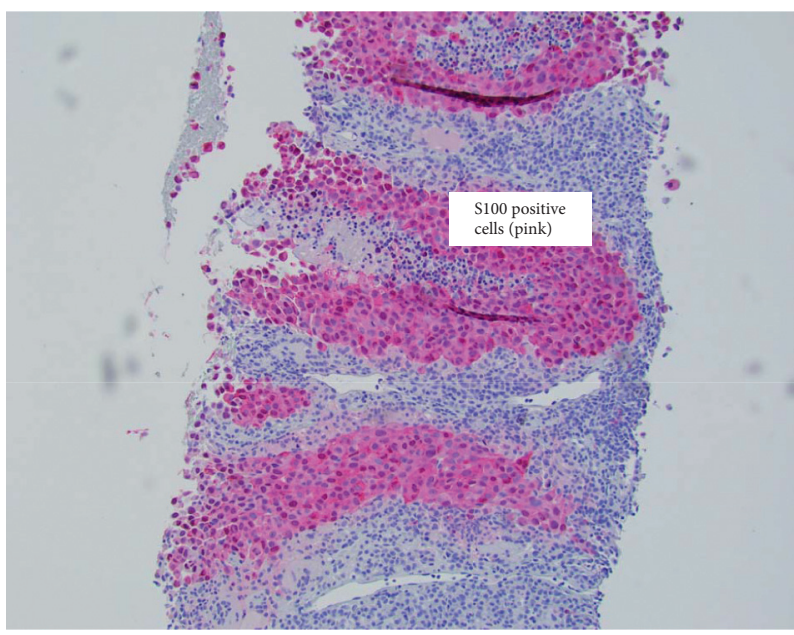

(c)

Figure 3: (a) Nest of tumor cells showing areas of necrosis (H\&E, original magnification $\times 100)$. (b) Immunohistochemical stain positive for SOX10 (H\&E, original magnification $\times 100)$. (c) Immunohistochemical stain positive for S100 (H\&E, original magnification $\times 100)$.

TABLE 1: Literature review of other reported cases of PRM.

\begin{tabular}{|c|c|c|c|}
\hline Case report & Initial presentation & Imaging results & Immunohistochemistry results \\
\hline $\begin{array}{l}\text { Primary retroperitoneal } \\
\text { malignant melanoma: a case } \\
\text { report [2] }\end{array}$ & $\begin{array}{l}\text { 18-y/o F with } 6 \text {-month } \mathrm{h} / \mathrm{o} \text { a } \\
\text { progressively enlarging mass } \\
\text { in the right upper abdomen } \\
\text { with no other symptoms }\end{array}$ & $\begin{array}{l}\text { CT scan of the abdomen showed } \\
\text { an irregular heterogeneous soft- } \\
\text { tissue density mass located in the } \\
\text { anterior pararenal space }\end{array}$ & $\begin{array}{c}\text { Immunohistochemical (IHC) staining } \\
\text { was positive for S100, human } \\
\text { melanoma black-45 (HMB45), and } \\
\text { melanin-A and mildly positive for } \\
\text { tyrosinase }\end{array}$ \\
\hline $\begin{array}{l}\text { Retroperitoneal malignant } \\
\text { melanoma-a curiosity [3] }\end{array}$ & $\begin{array}{l}\text { 76-y/o M with 2-week h/o } \\
\text { pain and distension of the } \\
\text { abdomen, followed by fever } \\
\text { and vomiting for } 4 \text { days }\end{array}$ & $\begin{array}{l}\text { CT scan of the abdomen revealed } \\
\text { a well-defined, } 8.6 \times 5.1 \mathrm{~cm} \text {, } \\
\text { heterogeneously enhancing mass } \\
\text { in the retroperitoneum }\end{array}$ & Not reported in case report \\
\hline $\begin{array}{l}\text { Primary retroperitoneal } \\
\text { malignant melanoma }[4]\end{array}$ & $\begin{array}{l}\text { 34-y/o F with 3-month h/o } \\
\text { recurrent abdominal pain and } \\
\text { distension, asthenia, anorexia, } \\
\text { vomiting, and fever }\end{array}$ & $\begin{array}{l}\text { CT scan of the abdomen } \\
\text { confirmed the presence of a large } \\
\text { retroperitoneal tumor measuring } \\
\qquad 8,22 \times 8,15 \mathrm{~cm}\end{array}$ & $\begin{array}{l}\text { IHC staining was positive for } \mathrm{S} 100 \text {, } \\
\text { HMB45, and melanin-A }\end{array}$ \\
\hline $\begin{array}{l}\text { A rare presentation of } \\
\text { melanoma as a } \\
\text { retroperitoneal mass: a case } \\
\text { report and a brief review of } \\
\text { the literature [5] }\end{array}$ & $\begin{array}{l}\text { 77-y/o } \mathrm{M} \text { with } 3 \text {-month } \mathrm{h} / \mathrm{o} \\
\text { fatigue, abdominal pain, } \\
\text { decreased appetite, and } 40-\mathrm{lb} \\
\text { weight loss }\end{array}$ & $\begin{array}{l}\text { PET/CT scan showed a large } \\
\text { heterogeneous, lobulated } \\
\text { subhepatic mass }\end{array}$ & $\begin{array}{l}\text { IHC staining was positive for vimentin, } \\
\text { HMB } 45 \text {, melanin-A, and } S 100\end{array}$ \\
\hline
\end{tabular}


TABLE 1: Continued.

\begin{tabular}{|c|c|c|c|}
\hline Case report & Initial presentation & Imaging results & Immunohistochemistry results \\
\hline $\begin{array}{l}\text { Ileus secondary to a } \\
\text { retroperitoneal malignant } \\
\text { melanoma [6] }\end{array}$ & $\begin{array}{c}\text { 77-h/o F with progressive } \\
\text { abdominal distension and } \\
\text { decreased appetite for } 4 \\
\text { months }\end{array}$ & $\begin{array}{c}\text { CTscan of the abdomen showed a } \\
\text { retroperitoneal tumor with } \\
\text { irregular margin and } \\
\text { heterogeneous density, } \\
\text { measuring approximately } \\
18.2 \times 21.5 \mathrm{~cm} \text { in the largest } \\
\text { section }\end{array}$ & $\begin{array}{l}\text { IHC staining was positive for } \mathrm{S} 100 \\
\text { protein, HMB45, and vimentin and } \\
\text { negative for cytokeratin AE1/AE3, } \\
\text { cytokeratin } 7 \text {, epithelial membrane } \\
\text { antigen, and CD34 }\end{array}$ \\
\hline $\begin{array}{l}\text { Primary retroperitoneal } \\
\text { melanoma presented in a rare } \\
\text { extracutaneous site for } \\
\text { malignant melanoma [7] }\end{array}$ & $\begin{array}{l}53-y / o ~ F \text { with } \\
\text { postmenopausal vaginal } \\
\text { bleeding }\end{array}$ & $\begin{array}{l}\text { Transvaginal ultrasound revealed } \\
\text { left-side complex pelvic mass } \\
\text { measuring } 4.3 \times 3.4 \times 3 \mathrm{~cm}\end{array}$ & $\begin{array}{l}\text { IHC staining was positive for HMB45, } \\
\text { melanin-A, and } S 100\end{array}$ \\
\hline $\begin{array}{l}\text { A rare presentation of } \\
\text { melanoma as a } \\
\text { retroperitoneal mass seen on } \\
\text { FDG PET [8] }\end{array}$ & $\begin{array}{l}55-y / o \mathrm{~F} \text { with } 4 \text {-week } \mathrm{h} / \mathrm{o} \\
\text { fatigue and abdominal pain }\end{array}$ & $\begin{array}{l}\text { Ultrasound and CTscan showed a } \\
\text { large heterogeneous mass in the } \\
\text { retroperitoneum, and PET/CT } \\
\text { images showed a hypermetabolic } \\
\text { retroperitoneal mass }\end{array}$ & $\begin{array}{c}\text { IHC staining was positive for HMB45, } \\
\text { S100, and melanin-A but negative for } \\
\text { CK and CgA; negative BRAF or C-kit } \\
\text { mutation }\end{array}$ \\
\hline
\end{tabular}

F, female; M, male; y/o, year-old; h/o, history of; HMB45, human melanoma black-45; CK, cytokeratin.

marker for renal and ovarian carcinomas [13] and protein GATA3 has been previously reported to be expressed in epithelial proliferations of the female genital tract [14].

Clear guidelines for the treatment of primary retroperitoneal malignant melanoma have not yet been defined due to the rarity of this disease, and therefore, therapy is based on evidence derived from the treatment of cutaneous melanoma. The mainstay of therapy for melanoma remains surgical resection, but if the tumor is surgically unresectable or in the case of more advanced disease, then systemic therapy is recommended. Vemurafenib and dabrafenib are small molecule inhibitors of BRAF kinase and are first-line treatment for BRAF mutation-positive melanoma [15]. Vemurafenib and dabrafenib are similar in efficacy, but dabrafenib is associated with less toxicity [16]. Another treatment regimen option includes programmed cell death protein 1 (PD-1) and programmed death-ligand 1(PD-L1) inhibitors, such as pembrolizumab and nivolumab, which are emerging as successful therapy for metastatic melanoma [15]. In conclusion, we report a case of primary retroperitoneal melanoma with involvement of the iliac artery and vein causing lower extremity edema. It is reasonable for physicians to take into consideration malignant melanoma when evaluating retroperitoneal masses.

\section{Data Availability}

No datasets were generated or analyzed during the current study.

\section{Conflicts of Interest}

The authors declare that they have no conflicts of interest.

\section{References}

[1] M. R. Hussein, "Extracutaneous malignant melanomas," Cancer Investigation, vol. 26, no. 5, pp. 516-534, 2008.

[2] G.-B. Liu, G.-Y. Wu, P. Ghimire, and Z.-P. Zhang, "Primary retroperitoneal malignant melanoma: a case report," Oncology Letters, vol. 2, no. 6, pp. 1107-1111, 2011.
[3] J. Pawale, A. P. Javalgi, R. Hiremath, V. D. Dombale, and M. H. Kansagara, "Retroperitoneal malignant melonoma-a curiosity," Journal of Clinical and Diagnostic Research, vol. 5, pp. 372-373, 2011.

[4] A. Zentar, R. Makhmari, H. Elkaoui et al., "Primary retroperitoneal malignant melanoma," The Pan African Medical Journal, vol. 12, p. 20, 2012.

[5] A. Randhawa, N. Sonpal, S. Machnicki, C. Spaccavento, and A. Novoselac, "A rare presentation of melanoma as a retroperitoneal mass: a case report and a brief review of the literature," Journal of Solid Tumors, vol. 3, no. 2, 2013.

[6] C.-F. Chen, C.-H. Chuang, C. Hu, and J.-Y. Wang, "Ileus secondary to a retroperitoneal malignant melanoma," Biomarkers and Genomic Medicine, vol. 5, no. 3, pp. 113-116, 2013.

[7] M. Alsharedi, N. B. Zgheib, Y. Khelfa, A. Raufi, N. Elmsherghi, and Y. Lebowicz, "Primary retroperitoneal melanoma presented in a rare extracutaneous site for malignant melanoma," Rare Tumors, vol. 8, no. 3, p. 6308, 2016.

[8] Y. Yao, W. Liu, Z. Zuo, and Z. Cheng, "A rare presentation of melanoma as a retroperitoneal mass seen on FDG PET," Clinical Nuclear Medicine, vol. 45, no. 4, pp. 324-325, 2020.

[9] M. Patnana, Y. Bronstein, J. Szklaruk et al., "Multimethod imaging, staging, and spectrum of manifestations of metastatic melanoma," Clinical Radiology, vol. 66, no. 3, pp. 224-236, 2011.

[10] S. J. Ohsie, G. P. Sarantopoulos, A. J. Cochran, and S. W. Binder, "Immunohistochemical characteristics of melanoma," Journal of Cutaneous Pathology, vol. 35, no. 5, pp. 433-444, 2008.

[11] B. Palla, A. Su, S. Binder, and S. Dry, "SOX10 expression distinguishes desmoplastic melanoma from its histologic mimics," The American Journal of Dermatopathology, vol. 35, no. 5, pp. 576-581, 2013.

[12] L. Cheng, A. Lopez-Beltran, F. Massari, G. T. MacLennan, and R. Montironi, "Molecular testing for BRAF mutations to inform melanoma treatment decisions: a move toward precision medicine," Modern Pathology, vol. 31, no. 1, pp. 24-38, 2018.

[13] D. Tacha, D. Zhou, and L. Cheng, "Expression of PAX8 in normal and neoplastic tissues," Applied Immunohistochemistry \& Molecular Morphology, vol. 19, no. 4, pp. 293-299, 2011. 
[14] G. E. Esheba, T. A. Longacre, K. A. Atkins, and J. P. Higgins, "Expression of the urothelial differentiation markers GATA3 and placental S100 (S100P) in female genital tract transitional cell proliferations," The American Journal of Surgical $\mathrm{Pa}$ thology, vol. 33, no. 3, pp. 347-353, 2009.

[15] M. M. Talag, M. Alsharedi, N. Bou Zgheib, and Y. Lebowicz, "Immunotherapy in a rare case of primary pelvic retroperitoneal melanoma," BMJ Case Reports, vol. 2016, Article ID 216450, 2016.

[16] A. M. Menzies, G. V. Long, and R. Murali, "Dabrafenib and its potential for the treatment of metastatic melanoma," Drug Design, Development and Therapy, vol. 6, pp. 391-405, 2012. 